
\title{
$\angle$ Research Square \\ Fast Feedback? Managing vulnerability in Emergency Departments through continuous improvement
}

Ricardo Mateo

University of Navarra

Liliana Neriz

University of Chile

Francisco Ramis

University of Bio Bio

Alicia Núñez ( $\square$ anunez@fen.uchile.cl )

University of Chile https://orcid.org/0000-0001-5407-5583

Hernan Bustamante

Hospital Padre Hurtado

Carmen Mateo

Hospital la Candelaria

Research article

Keywords: Vulnerability; Management; Emergency Departments; Fast feedback; Performance

Posted Date: August 20th, 2019

DOl: https://doi.org/10.21203/rs.2.13225/v1

License: (1) This work is licensed under a Creative Commons Attribution 4.0 International License.

Read Full License 


\section{Abstract}

Background Waiting time for physician attention is considered emergency care-sensitive, but still many emergency departments (EDs) attend their patients outside of the standard recommended. Objectives The objective of this research is to make a contribution for managing continuous improvement in EDs based on providing fast feedback using a new normalized variable named vulnerability. Methods This research has analyzed the levels of census, efficiency and vulnerability with which an ED works. The data set contains information regarding 53,175 individuals attended in an ED in Chile during 2013. A regression model was conducted to explain vulnerability. In order to carry out the analysis census, efficiency and vulnerability variables were calculated for each patient attended. The model has explained $63 \%$ of vulnerability. Results $40 \%$ of ED patients were attended after the wait time recommended by ESI and with efficiency levels lower than $40 \%$. According to our results, efficiency, census, diagnostic track and months explain vulnerability. Conclusions This study allows us to manage EDs by using a new variable named vulnerability. Vulnerability provides fast feedback for healthcare professionals in order to develop a continuous improvement policy. This could increase professional commitment for continuous improvement and therefore decrease morbidity and mortality in any ED.

\section{Background}

A full accessibility of Emergency Departments (EDs) for all the population is the best guaranty for an excellent urgent healthcare system. Nevertheless, the number of patient visits to EDs has increased, causing crowding, increasing patient vulnerability and reducing efficiency. This threatens access to quality care and safety in emergency services not only for those who need them the most but for everyone. In this millennium several authors have been concerned about the problem in the emergency medicine literature ${ }^{1-3}$.

ED crowding is the result of a mismatch between supply and demand in the emergency healthcare system. The bottom line is simple: ED crowding is a serious issue that affects millions of ill citizens that need urgent care around the world. This paper focuses on a new concept to manage EDs providing fast feedback by measuring patient vulnerability for continuous improvement.

Crowding could be defined in an ED as the situation where the number of patients being attended or waiting to be attended exceeds its capacity to provide care on time. This situation may be the result of excess demand or a lack of attention from the ED. Crowding has been described as a serious patient safety problem ${ }^{4-6}$. According to Espinosa, the main causes for crowding are hospital related factors such as waiting for: physicians, lab exams results, bed and/or transportation to a bed in the hospital, procedures performed outside the ED or consultation with a specialist ${ }^{7}$.

Patient vulnerability is defined as the compliance with the standard wait time. Therefore, it can be measured as the time from triage until physician examination divided by the standard wait time, given the patient Emergency Severity Index (ESI) defined by each hospital. 
In an ED, wait time for a physician examination is a key variable for explaining the outcomes of the medical attention. In the most critical patients any medical attention delay may increase patient vulnerability, risk of mortality and reduce patient safety. Therefore, on time attention may reduce patient vulnerability. Burnström et ál. stated that physician-led team triage resulted in a reduction in the wait time for a physician, shorter length of stay and decreases in mortality rates after 7 and 30 days from their ED departure ${ }^{8}$.

Efficiency is one of the most important objectives to reach excellence in a healthcare system ${ }^{9}$. Efficiency means optimal use of all personnel and resources in order to attend patients, reduce cycle time of attention and avoid any delay. Efficiency is the ratio of value added time (total time of all value activities provided for each patient) divided by Cycle Time (patient total time in the ED from arrival to departure). Therefore, continuous improvement in efficiency should reduce the Length of Stay (LOS), waiting times and crowding.

Nevertheless, an ED could only be efficient if the demand does not exceed its capacity. The ED can increase the capacity of medical attention by two means. In the first place, by increasing professional capabilities with more efforts to detect, analyze and improve operations. The second would be based on using more resources. Apparently, the best solution to improve the lack of capacity of an ED starts by increasing professional capabilities and then by adding more resources.

Efficiency and crowding generate a great impact on patient vulnerability but few efforts have been made to strive on this issue ${ }^{3}$. Our proposal is to manage EDs with daily continuous improvement strategies against all problems that harm the vulnerability of patients.

Goals of This Investigation

The goal of this research is to promote patient vulnerability as a new fast feedback and normalized variable for managing ED. This may enhance continuous improvement in ED and to engage all healthcare professionals.

\section{Methods}

\section{Setting}

Data from one state owned ED located in Santiago of Chile was used for the empirical analysis of the paper. The dataset includes 53,175 individual-level valid data of patients attended in the ED for a year. The dataset covers information regarding on time scheduling of ED attention, diagnostic and ESI priority index. 
We conducted correlation and linear regression analysis. For the linear regression we used a logarithmic transformation of the dependent variable (vulnerability). According to our model vulnerability will be explained by efficiency, census, patient index, diagnostic track and arrival month, as follows:

$\operatorname{Ln}\left(u_{i}\right)=a+\gamma_{*} \eta_{i}+\delta_{\star} N_{i}+C_{i}+$ IPCIflexsi $i_{i}+$ Imonth $_{i}+\varepsilon_{i} \quad i=1 \ldots 53,175$

The model is normally distributed; homoscedasticity and multicollinearity have been checked for all variables. Stata 12 was used to carry out the analysis.

Both efficiency rates for the patient arrival time at the ED and vulnerability were built specifically for this research. Some variables were also simulated using Flexsim Healthcare software. The full description of the variables is included in Table 1.

$<$ Insert Table 1, here>

Analyses were conducted on all day visits (ie, those registered between 0:00 am and 24:00 pm) between January 1, 2013, and December 31, 2013.

\section{Results}

There is a strong negative correlation between efficiency and the census and vulnerability variables $(-0.3241$ and -0.4391 respectively, $p<0.01)$. There is also a positive correlation between the vulnerability and census variables $(0.2598, p<0.01)$.

As shown in Table 2 vulnerability is higher at lower efficiency levels. For example, the average vulnerability for patients who arrived at EDs when efficiency is greater than $90 \%$ is 0.37 while vulnerability for people who arrived at EDs when efficiency is lower than $20 \%$ and greater than $10 \%$ is 7.07 . When the ED efficiency level is higher than $40 \%$ the mean of vulnerability is lower than 1 . Vulnerability values below 1 indicate that the patient was attended according to the standard wait time defined by ESI.

Table 2 also presents the mean of vulnerability and efficiency clustered by census. A relationship between vulnerability, efficiency and census could be observed. For instance, when census is lower than 50 patients, vulnerability is lower than 1 , which means that those patients are attended according to the ESI standard. Inversely, when census is higher than 50 , then the vulnerability reaches values over 1 . This 
situation can be explained by the ED resources capacity, which includes physicians, nurses, beds, examination rooms, etc.

As we have previously shown there is a relationship between efficiency, census and vulnerability. In Table 3 a linear regression model considering vulnerability as a dependent variable is presented. The regression model has a r-square of $63 \%$. There is a significant relationship between vulnerability and the efficiency and census variables, some diagnostic tracks and some months. If efficiency increases by 1 , then the natural logarithm of vulnerability decreases. On the other hand, as census increases vulnerability also increases.

\section{$<$ Insert Table 2 and 3, here>}

\section{Limitations}

Some limitations of this study include the analysis of the vulnerability variable in just one hospital in Chile and the need to simulate some data given the information available in this institution.

\section{Discussion And Conclusions}

Wait time for physician attention is considered emergency care-sensitive, but still many EDs attend their patients outside of the standard wait time. One of the main problems for managing wait time is the heterogeneity of the value of time for different ESI. For example, one minute of waiting time is not the same for a $\mathrm{C} 1$ patient than for a C5 patient.

This research has introduced a new variable named vulnerability that normalizes time in accordance with the emergency. Vulnerability is computed normalizing patients by dividing patients waiting time with the standard wait time given the ESI. As all patients are normalized to the same variable (standard wait time associated to the ESI Triage), it is possible to monitor every patient and to trigger a continuous improvement process when a delay exceeds a time limit defined by the ED. Fast feedback with red, yellow and green lights for every patient can be developed by any ED, so they can detect those cases (red light cases) that must be analyzed in order to obtain improvements. Therefore, vulnerability management in EDs enables the development of a continuous improvement policy by facilitating fast feedback.

Daily continuous improvement is important because it increases the capability of ED professionals to solve multi-factorial problems in their daily operations. Selecting problems, analyzing root causes, searching for possible solutions and implementing improvements will create a new way of enhancing quality and safety in EDs. Continuous improvement is an easy to use methodology that has been performed in hospitals successfully ${ }^{10}$. Stelson et ál., have identified managerial support, communication, 
and professional commitment as important factors for continuous improvement success ${ }^{10}$. In the case of an ED, patient vulnerability can have two different impacts: 1 ) when the patient is still in the ED, the vulnerability light (red light) could be an alert for healthcare professionals to give additional support to the patients that are exceeding the limit waiting time defined by the ED; and 2) when the patient leaves the ED, the vulnerability light can activate continuous improvement processes according to the resources available and its priorities.

It is important that any daily continuous improvement policy should be established by the ED and not just an isolated tool. The definition of a policy will upgrade continuous improvement but will depend on the healthcare professional capabilities and their participation.

The major contribution of this paper is to focus on a new concept (vulnerability) as the target for managing internal administrative problems and not only clinical problems associated to crowding and efficiency. The main results can be summarized as follows. First, we quantified the impact on vulnerability by clustering efficiency and census for each patient. In fact, there is a negative impact on vulnerability when efficiency is lower and when census is higher. Second, we ran a linear regression where we found that efficiency and census are significant variables. We also found that diagnostic tracks and months are variables that can explain vulnerability. Based on these results, we can conclude that efficiency has a negative effect on vulnerability and an inverse effect on census.

Efficiency may be considered as a patient safety clinic variable because it not only affects daily operation activities of the ED but also patient safety, increasing their vulnerability.

Future research should include the study of vulnerability in other EDs and the inclusion of the assessment of two states of the ED capacity (idle capacity and full capacity), to evaluate the impact that may have on vulnerability. In addition, we should study the results of applying vulnerability lights and measure their impact on ED performance..

\section{Abbreviations}

$\mathrm{ED}=$ Emergency Department

$\mathrm{ESI}=$ Emergency Severity Index

LOS= Length of Stay

\section{Declarations}

\section{Ethics of Approval and Consent to Participate}

Not applicable 
Acknowledgments: We thanks Conicyt for the funding provided and the ED that participated in this study.

\section{Consent for publication}

Not applicable

\section{Availability of data and materials}

All data generated or analyzed during this study are included in this published article.

\section{Competing Interests}

The authors have declared that no competing interests exist.

\section{Funding}

The National Commission for Scientific and Technological Research CONICYT - FONDEF, Santiago, Chile, [Grant Number: IT13i10003]

\section{Author's contribution}

The contribution of the author was as followed: RM developed the original research idea and questions, obtained the data for this study, conducted data analysis, interpreted the results, and wrote the manuscript. LN contributed to the original research idea and questions and contributed to the writing and revisions of the manuscript. AN conducted data analysis, interpreted the results, and contributed to the writing and revisions of the manuscript. HB contributed with data and contributed writing and reviewing the manuscript. CM contributed interpreting the results, and reviewing the manuscript. All authors read and approved the final manuscript.

\section{References}

1 Derlet RW, Richards JR. Overcrowding in the nation's emergency departments: Complex causes and disturbing effects. Annals of Emergency Medicine 2000; 35: 63-68

2 Derlet RW. Overcrowding in emergency departments: Increased demand and decreased capacity. Annals of Emergency Medicine 2002; 39: 430-432 
3 Juan A, Enjamio E, Moya C, Fortea CG, Castellanos J, Mas JRP, Milan JM, Lores L, Urgelles J, Robles B, Bou E, Romero C, Mendez J, Saavedra J, Cespedes M, Morera M, Vera R, Ferriz C, Tor S, Ramon R. Impact of hospital management measures on improving the efficiency of bed allocation and reducing emergency department overcrowding. Emergencias 2010; 22: 249-253

$4 \quad$ McCarthy ML. Overcrowding in emergency departments and adverse outcomes. British Medical Journal $2011 ; 342$

5 Hoot NR, Aronsky D. Systematic review of emergency department crowding: Causes, effects, and solutions. Annals of Emergency Medicine 2008; 52: 126-136

6 Carter EJ, Pouch SM, Larson EL. The Relationship Between Emergency Department Crowding and Patient Outcomes: A Systematic Review. Journal of Nursing Scholarship 2014; 46: 106-115

7 Espinosa G, Miro 0, Sanchez M, Coll-vinent B, Milla J. Effects of external and internal factors on emergency department overcrowding. Annals of Emergency Medicine 2002; 39: 693-695

8 Burstrom L, Engstrom ML, Castren M, Wiklund T, Enlund M. Improved quality and efficiency after the introduction of physician-led team triage in an emergency department. Upsala Journal of Medical Sciences 2016; 121: 38-44

9 Ward MJ, Farley H, Khare RK, Kulstad E, Mutter RL, Shesser R, Stone-Griffith S. Achieving Efficiency in Crowded Emergency Departments: A Research Agenda. Academic Emergency Medicine 2011; 18: 13031312

10 Stelson P, Hille J, Eseonu C, Doolen T. What drives continuous improvement project success in healthcare? International Journal of Health Care Quality Assurance 2017; 30: 43-57

\section{Tables}

Table 1: Description of the variables

\begin{tabular}{|c|c|c|c|}
\hline Variable & Name & Description & Type of Variable \\
\hline \multirow[t]{3}{*}{$\mathrm{v}_{\mathrm{i}}$} & Vulnerability & Patient waiting time (PWT) & Continuous \\
\hline & & divided by the standard wait time & \\
\hline & & given the patient ESI & \\
\hline
\end{tabular}




$\begin{array}{lll}\text { PWT Patient waiting } & \text { The time from triage until } & \text { Continuous } \\ & \text { physician examination } & \text { Continuous } \\ \eta_{\mathrm{i}} & \text { Ratio of Value Added Time } \quad \text { /Simulated } \\ & \text { (VAT) divided by Cycle }(\mathrm{CT}) \text { of ED at the } \\ & \text { patient arrival time }(\eta \text { is } \\ & \text { simulated for patient } \mathrm{i})\end{array}$

$\begin{array}{llll}\text { VAT }_{\mathrm{i}} \text { Value Added Time } & \begin{array}{c}\text { Total time of all value added } \\ \text { activities provided by the ED }\end{array} & \text { /Simulated } \\ & \text { Cycle Time the patient i } & \text { Continuous } \\ \mathrm{CT}_{\mathrm{i}} & \text { Total patient i arrival time to } & \text { Continuous } \\ & & \text { departure time in the ED } & \text { /Simulated } \\ \mathrm{N}_{\mathrm{i}} & \text { Census } & \text { Number of patients that are } & \text { Continuous }\end{array}$

in the ED at the time of patient $\mathrm{i}$

arrival, including patient i

$\mathrm{AD}_{\mathrm{i}} \quad$ Admission time $\quad$ Patient Arrival time i at the ED Continuous

$\mathrm{TTD}_{\mathrm{i}} \quad$ Time to doctor Starting attention time for Continuous

patient i

$\mathrm{C}_{\mathrm{i}} \quad$ Patient Index $\quad$ ESI for patient I Continuous

IPCIflexsi $_{\mathrm{i}} \quad$ Diagnostic track Diagnostic for patient i Categorical

(28 diagnostic tracks)

Month $_{\mathrm{i}} \quad$ Month Month of patient i arrival Dummy 
Note: Simulation was done using Flexsim Healthcare software based on real patient arrivals and 28 diagnostic tracks. Each diagnosis track has its own analysis of activities and movements.

Table 2: Vulnerability and Census by clustering efficiency and census

\begin{tabular}{|c|c|c|c|}
\hline $\begin{array}{l}\text { Cluster \% } \\
\text { Efficiency }\end{array}$ & $\begin{array}{l}\text { Efficiency } \\
\text { mean }\left(\eta_{i}\right)\end{array}$ & $\begin{array}{l}\text { Vulnerability } \\
\text { mean }\left(v_{i}\right)\end{array}$ & Number of patients \\
\hline$\eta_{\mathrm{i}}<=10 \%$ & 0.0577 & 5.83 & 7,970 \\
\hline $10 \%<\eta_{\mathrm{i}}<=20 \%$ & 0.1455 & 7.07 & 4,797 \\
\hline $20 \%<\eta_{\mathrm{i}}<=30 \%$ & 0.2516 & 3.55 & 3,739 \\
\hline $30 \%<\eta_{\mathrm{i}}<=40 \%$ & 0.3531 & 1.58 & 4,510 \\
\hline $40 \%<\eta_{\mathrm{i}}<=50 \%$ & 0.4553 & 0.53 & 9,434 \\
\hline $50 \%<\eta_{\mathrm{i}}<=60 \%$ & 0.5459 & 0.37 & 8,117 \\
\hline $60 \%<\eta_{\mathrm{i}}<=70 \%$ & 0.6457 & 0.32 & 5,166 \\
\hline $70 \%<\eta_{\mathrm{i}}<=80 \%$ & 0.7494 & 0.28 & 3,897 \\
\hline $80 \%<\eta_{\mathrm{i}}<=90 \%$ & 0.8516 & 0.25 & 3,762 \\
\hline $90 \%<\eta_{\mathrm{i}}<=100 \%$ & 0.9263 & 0.37 & 1,783 \\
\hline Total & 0.4425 & 2.13 & 53,175 \\
\hline Cluster & Efficiency & Vulnerability & Number of \\
\hline Census $\left(\mathrm{N}_{\mathrm{i}}\right)$ & Mean $\left(\eta_{\mathrm{i}}\right)$ & mean $\left(v_{i}\right)$ & patients \\
\hline 11 to 20 & 0.5592 & 0.5440 & 62 \\
\hline 21 to 30 & 0.5920 & 0.5857 & 910 \\
\hline 31 to 40 & 0.5675 & 0.7586 & 5,319 \\
\hline 41 to 50 & 0.5220 & 0.9988 & 12,020 \\
\hline 51 to 60 & 0.4557 & 1.6753 & 13,064 \\
\hline 61 to 70 & 0.3857 & 2.6270 & 10,592 \\
\hline 71 to 80 & 0.3393 & 3.6251 & 6,718 \\
\hline 81 to 90 & 0.3052 & 4.4948 & 2,908 \\
\hline 91 to 100 & 0.2861 & 5.9278 & 1,070 \\
\hline 101 to 110 & 0.2889 & 6.7434 & 451 \\
\hline 111 to 120 & 0.3590 & 4.5907 & 61 \\
\hline Total & 0.4425 & 2.1327 & 53,175 \\
\hline
\end{tabular}




\begin{tabular}{|c|c|c|c|c|c|}
\hline Ln(vulnerability) & Coefficient & Std. Err. & $\mathrm{t}$ & \multicolumn{2}{|c|}{ [95\% Conf. Interval] } \\
\hline Efficiency & -5.6070 & 0.0233 & $-240.13^{* * *}$ & -5.6528 & -5.5612 \\
\hline Census & 0.0060 & 0.0002 & $21.51^{* * *}$ & 0.0054 & 0.0065 \\
\hline IPCIflexsi_2 & 0.4638 & 0.0561 & $8.26^{* * *}$ & 0.3537 & 00.5738 \\
\hline IPCIflexsi_3 & -0.4730 & 0.0331 & $-14.28^{* * *}$ & -0.5379 & -0.4081 \\
\hline IPCIflexsi_4 & 0.8385 & 0.0312 & $26.83^{* * *}$ & 0.7772 & 0.8998 \\
\hline IPCIflexsi_5 & 1.5037 & 0.0704 & $21.35^{* * *}$ & 1.3656 & 1.6417 \\
\hline IPCIflexsi_6 & 1.0724 & 0.0298 & $35.99^{* * *}$ & 1.0140 & 1.1308 \\
\hline IPCIflexsi_7 & 0.3257 & 0.0318 & $10.23^{* * *}$ & 0.2633 & 0.3881 \\
\hline IPCIflexsi_8 & 0.2482 & 0.0380 & $6.52^{* * *}$ & 0.1736 & 0.3228 \\
\hline IPCIflexsi_9 & 1.6812 & 0.0352 & $47.66^{* * *}$ & 1.6121 & 1.7503 \\
\hline IPCIflexsi_10 & 0.3249 & 0.0567 & $5.72^{* * *}$ & 0.2136 & 0.4362 \\
\hline IPCIflexsi_11 & 1.1153 & 0.0409 & $27.21^{* * *}$ & 1.0350 & 1.1957 \\
\hline IPCIflexsi_12 & 1.1075 & 0.0671 & $16.49^{* * *}$ & 0.9758 & 1.2392 \\
\hline IPCIflexsi_13 & -0.4444 & 0.0164 & $-27.05^{* * *}$ & -0.4766 & -0.4122 \\
\hline IPCIflexsi_14 & 0.4217 & 0.0362 & $11.63^{* * *}$ & 0.3506 & 0.4927 \\
\hline IPCIflexsi_15 & 0.2400 & 0.0470 & $5.11^{* * *}$ & 0.1479 & 0.3322 \\
\hline IPCIflexsi_16 & -0.0836 & 0.0130 & $-6.41^{* * *}$ & -0.1092 & -0.0580 \\
\hline IPCIflexsi_17 & 1.2226 & 0.0170 & $71.55^{* * *}$ & 1.1891 & 1.2561 \\
\hline IPCIflexsi_18 & 0.6491 & 0.0264 & $24.57^{* * *}$ & 0.5973 & 0.7009 \\
\hline IPCIflexsi_19 & -1.5560 & 0.0171 & $-90.53^{* * *}$ & -1.5897 & -1.5223 \\
\hline IPCIflexsi_20 & -0.5264 & 0.0199 & $-26.43^{* * *}$ & -0.5655 & -0.4874 \\
\hline IPCIflexsi_21 & -0.0341 & 0.0295 & $-1.16^{* * *}$ & -0.0920 & 0.0236 \\
\hline IPCIflexsi_22 & 0.5176 & 0.0202 & $25.62^{* * *}$ & 0.4780 & 0.5572 \\
\hline IPCIflexsi_23 & 0.9768 & 0.0400 & $24.39^{* * *}$ & 0.8983 & 1.0553 \\
\hline IPCIflexsi_24 & 1.4488 & 0.0380 & $38.03^{* * *}$ & 1.3741 & 1.5234 \\
\hline IPCIflexsi_25 & 1.0122 & 0.0346 & $29.24^{* * *}$ & 0.9444 & 1.0801 \\
\hline IPCIflexsi_26 & 0.1819 & 0.0394 & $4.61^{* * *}$ & 0.1046 & 0.2592 \\
\hline IPCIflexsi_27 & 1.1132 & 0.0481 & 23.10 & 1.0187 & 1.2077 \\
\hline
\end{tabular}

Table 3: Linear Regression Model for Vulnerability (Continue) 


\begin{tabular}{|l|l|l|l|l|l|}
\hline Ln(vulnerability) & Coefficient & Std. Err. & $\mathrm{t}$ & \multicolumn{2}{|l|}{ [95\% Conf. Interval] } \\
\hline IPCIflexsi_28 & 2.8054 & 0.0325 & $86.19^{* * *}$ & 2.7416 & 2.8692 \\
\hline Month_2 & -0.0060 & 0.0183 & -0.33 & -0.0420 & 0.0299 \\
\hline Month_3 & 0.0238 & 0.0176 & 1.35 & -0.0107 & 0.0585 \\
\hline Month_4 & -0.0176 & 0.0179 & -0.99 & -0.0528 & 0.0174 \\
\hline Month_5 & -0.0757 & 0.0182 & $-4.14^{* * *}$ & -0.1115 & -0.0398 \\
\hline Month_6 & -0.1424 & 0.0185 & $-7.67^{* * *}$ & -0.1788 & -0.1061 \\
\hline Month_7 & -0.1572 & 0.0198 & $-7.90^{* * *}$ & -0.1962 & -0.1182 \\
\hline Month_8 & -0.2835 & 0.0183 & $-15.49^{* * *}$ & -0.3194 & -0.2476 \\
\hline Month_9 & -0.2053 & 0.0187 & $-10.97^{* * *}$ & -0.2420 & -0.1686 \\
\hline Month_10 & -0.2479 & 0.0182 & $-13.56^{* * *}$ & -0.2838 & -0.2121 \\
\hline Month_11 & -0.2561 & 0.0185 & $-13.79^{* * *}$ & -0.2925 & -0.2197 \\
\hline Month_12 & -0.2757 & 0.0186 & $-14.81^{* * *}$ & -0.3122 & -0.2392 \\
\hline cons & 1.7386 & 0.0291 & 59.66 & 1.6815 & 1.7957 \\
\hline Sample & 53,175 & & & & \\
\hline F (40, 53134) & 2271.53 & 0.6310 & & & \\
\hline R-square & & & & & \\
\hline
\end{tabular}

